\title{
GRUPOS COLABORATIVOS COMO FERRAMENTA NA REESTRUTURAÇÃO DO MODELO DIDÁTICO DO PROFESSOR DE QUÍMICA
}

\section{Collaborative groups as a tool in the restructuring of the didactic model chemistry teacher}

\author{
João Batista dos Santos Júnior ${ }^{1}$ • Maria Eunice Ribeiro Marcondes ${ }^{2}$
}

Resumo: Esta investigação apresenta os resultados de um estudo sobre como um projeto colaborativo envolvendo professores de Química pode servir como instrumento para a reflexão dos docentes sobre as suas concepções e práticas pedagógicas, e, também, para resgatar deficiências na formação inicial destes que, por ventura, ainda não foram sanadas no exercício da docência. A análise das reestruturações de cada docente foi feita a partir de seus respectivos modelos didáticos. Para tal, foi utilizado um inventário para identificar esses modelos, de modo que foi possível compará-los antes e depois dos trabalhos do grupo de aprendizagem colaborativa.

Palavras-chave: Ensino de química. Grupo colaborativo. Modelo didático. Cultura profissional. Formação de professores.

\begin{abstract}
This research presents the results of study on how a collaborative project involving Chemistry teachers can serve as a tool for reflection by the teachers on their conceptions and teaching practices and also to throw some light on deficiencies in the initial training that may not have been remedied in the course of their teaching career. The analysis of each teacher's restructurings was based on their didactic models and on an inventory used to identify these models, so that it was possible to compare them before and after the group's collaborative learning.
\end{abstract}

Keywords: Chemistry teaching. Collaborative groups. Didactic model. Professional culture. Teacher education.

\footnotetext{
${ }^{1}$ Universidade Federal de São Carlos (UFSCar), Departamento de Física, Química e Matemática, campus Sorocaba, Rodovia João Leme dos Santos, Km 110, Bairro do Itinga, CEP 18052-780, Sorocaba, SP, Brasil. Email: joaobats@ufscar.br

${ }^{2}$ Universidade de São Paulo (USP), Instituto de Química, São Paulo, SP, Brasil.
} 


\section{Introdução}

É consensual que a formação de professores, tanto inicial como continuada, precisa de reformulações para atender as expectativas emergentes da educação. Em relação ao currículo das licenciaturas, Abib (2002) e Schnetzler (2002) apontam que a desconexão entre as chamadas disciplinas específicas e as disciplinadas pedagógicas possui características de um currículo baseado na racionalidade técnica, fato que pode contribuir para que os futuros professores tenham uma visão reducionista do processo de ensino e aprendizagem.

Em relação à formação continuada, alguns trabalhos apontam o predomínio da concepção de que o docente tem um papel passivo no que diz respeito a sua própria formação profissional. Neste sentido, Lacerda (2002) alerta que o docente é frequentemente visto como um indivíduo incapaz de produzir conhecimento. Freitas e Villani (2002) argumentam que, na organização de cursos e projetos de formação continuada, o docente é visto ora como um implementador de políticas educacionais ora como consumidor de tais cursos.

Para Sacristán (1999), a formação do professor é fundamental para a renovação de um sistema educativo. Devido a sua amplitude, o conceito de formação docente pode ter múltiplos sentidos (ALMEIDA, 2006). Para Garcia (1995), o conceito de formação profissional refere-se potencialmente ao ato de aquisição de saberes, do saber-fazer e do saber-ser. Almeida (2006) chama a atenção para que a formação seja vista como um processo que pressupõe crescimento e desenvolvimento, tanto pessoal como cultural, não em um enfoque apenas técnico, mas reflexivo, no qual o sujeito pode contribuir com seus conhecimentos e experiências em seu próprio processo formativo.

Nessa perspectiva, o conceito de desenvolvimento profissional do professor vem sendo tema de inúmeros trabalhos (IMBERNÓN, 1998; LIBÂNEO; PIMENTA, 1999; VÁZQUEZ BERNAL; JIMÉNEZ PÉREZ; MELLADO JIMÉNEZ, 2007) que, em comum, indicam a necessidade da inserção do indivíduo em processos metacognitivos sobre seus conhecimentos, ações e pensamentos (MELLADO, 2003).

Parece evidente a urgência pela busca de um modelo formativo docente que propicie não apenas o ingresso nas escolas de professores mais preparados para enfrentar os desafios relativos à docência, como, também, docentes conscientes da importância de regularem a sua formação continuada.

Nesta interface, a colaboração entre professores pode ser um recurso importante para o aprimoramento da formação docente. Deve-se considerar que processos metacognitivos (MELLADO, 2003) e reflexivos (FURIÓ; CARNICER, 2002) podem ser alcançados em projetos colaborativos.

Segundo Sadalla et al. (2005), a reflexão de um grupo de professores sobre suas respectivas práticas pedagógicas pode produzir o esclarecimento de dúvidas individuais, o rompimento com estereótipos e a identificação de obstáculos que poderiam impedir o desenvolvimento profissional, a resolução e o enfrentamento de problemas, e, ainda, a produção de conhecimento.

Muitos estudos apontam que as concepções que os docentes têm sobre o ensino e a aprendizagem podem se constituir como um obstáculo à produção de práticas inovadoras (BEACH; PEARSON, 1998; FURIÓ; CARNICER, 2002; GENÉ; GIL, 1987; GIL-PEREZ; CARVALHO, 1995). 
Wartha e Gramacho (2007) apontam para a necessidade de se inserirem, na formação docente, situações para o exercício da reflexão sobre suas próprias concepções. Nessa linha, Pimenta (2008) alerta para a necessidade de se criarem condições para que os professores possam modificar suas práticas pedagógicas.

Assim, é estudada, nessa investigação, a efetividade da colaboração entre professores, como recurso para a reestruturação dos modelos didáticos (GARCÍA PÉREZ, 2000) de um grupo de docentes de Química. Para esse fim, foi criado um grupo colaborativo que visava discutir as dificuldades no ensino e a obtenção de soluções para essas dificuldades, e, também, resgatar deficiências oriundas da formação inicial e que não foram dirimidas em cursos de capacitação oferecidos aos docentes.

A reestruturação do modelo didático do professor é analisada ao longo do trabalho do grupo, assumindo-se que esse modelo encerra elementos que constituem a prática pedagógica do docente. Nessa perspectiva, pode-se entender a reorganização do modelo didático do professor como indício de uma possível ressignificação de sua prática docente.

\section{Referencial teórico}

A ideia de modelo didático tem sido utilizada como uma tentativa de representar os fazeres pedagógicos dos professores (PORLÁN ARIZA; RIVERO GARCÍA; MARTÍN DEL POZO, 1997, 1998; GARCÍA PÉREZ, 2000). As tomadas de decisões, nem sempre conscientes, que permeiam o fazer pedagógico de um professor, estão impregnadas por suas crenças e saberes tácitos (GIL-PÉREZ; CARVALHO,1995), esse fazer pedagógico é o que se denomina modelo didático do professor.

O modelo didático é um esquema mediador entre a realidade e o pensamento do professor, uma estrutura onde se organiza o conhecimento, e terá sempre um caráter provisório e de aproximação com uma realidade. Por outro lado, é também um recurso de desenvolvimento e de fundamentação para a prática do professor (CHROBAK, 2006); a ideia de modelo didático permite abordar (de maneira simplificada, como qualquer modelo) a complexidade da realidade escolar, ao mesmo tempo em que ajuda a propor procedimentos de intervenção na mesma e a fundamentar, portanto, linhas de investigação educativa e de formação dos professores (GARCÍA PÉREZ, 2000).

Segundo García Pérez (2000), um modelo didático é um produto constituído pelas crenças, pela cultura, pelas relações sociais que permeiam o processo de ensino e aprendizagem e a intencionalidade do professor em ensinar seus alunos. A construção desses modelos está baseada em cinco dimensões didáticas: qual é o objetivo do ensino? O que deve ser ensinado ao aluno? Qual é a relevância das ideias e interesses do aluno? Como ensinar? Como avaliar?

De acordo com essas dimensões, o pesquisador propõe quatro modelos didáticos: o tradicional, o tecnológico, o espontaneísta e o alternativo.

No modelo tradicional, baseado em concepções advindas de uma perspectiva da transmissão cultural, há uma supervalorização dos conteúdos, os alunos são avaliados em relação à assimilação desses conteúdos de maneira individualizada; o papel do aluno no processo é passivo, ou seja, cabe a ele acatar e fazer o que o professor determina, não tendo maior 
contribuição no planejamento das atividades, ao docente cabe, além do planejamento, controlar a disciplina da sala.

O modelo tecnológico seria uma espécie de modernização do modelo tradicional, sendo caracterizado pela incorporação de conteúdos ditos mais modernos vinculados a temáticas sociais e ambientais, pelo cumprimento de objetivos e metas traçados no planejamento feito pelo professor. As concepções dos alunos, quando consideradas no processo, são vistas como erros conceituais e seu papel é executar todas as atividades programadas pelo professor, que, nesse modelo, tem a função de direcionar o andamento das atividades programadas.

O modelo espontaneísta pode ser visto como um contraponto ao modelo tradicional, pois o aluno é tido como foco do processo, sendo valorizado o desenvolvimento de habilidades e competências. Os interesses do aluno são um componente fundamental nesse modelo didático, pois, é a partir deles, juntamente com a realidade na qual estão inseridos, que o professor elabora seu planejamento. Os alunos têm um papel ativo, sendo esperado que eles sejam capazes de aprender determinados conteúdos por descoberta, e compreender o contexto social em que vivem. O professor não tem um papel gerencial do processo, sendo visto como uma liderança que coordena o trabalho dos alunos.

E, finalmente, o modelo alternativo, que visa à ampliação da capacidade de compreensão do aluno sobre o mundo e o seu protagonismo sobre a realidade que o cerca. Tanto os professores quanto os alunos exercem um papel ativo, os primeiros como investigadores de suas práticas pedagógicas, e os segundos, como construtores e reconstrutores de suas aprendizagens, que são alcançadas pela implantação de situações-problema que exigem do aluno posturas investigativas para a sua resolução. As ideias e interesses dos alunos são considerados nesse modelo didático.

Existem evidências de que o professor, ao pensar sobre o seu próprio ato docente, se apropria de determinadas características desses quatro modelos, constituindo, assim, um modelo pessoal didático divergente dos pressupostos (GUIMARÃES; ECHEVERRÍA; MORAES, 2006; SANTOS JR.; MARCONDES, 2008).

\section{A colaboração entre professores}

Fullan e Hargreaves (1998) alertam que o individualismo de um professor pode ser consequência da adaptação do docente à estrutura da escola, aos seus horários, à sobrecarga de trabalho e fatores históricos da profissão. Hargreaves (1999) argumenta que sensações como insegurança, inferioridade e desproteção, podem remeter o docente ao isolamento.

É fato que: muitos professores lecionam em duas ou mais escolas; os horários das aulas e demais atividades escolares acabam quase que invariavelmente sendo uma adaptação para o funcionamento dessa escola; os docentes têm muita dificuldade em manter suas responsabilidades em dia, devido ao número excessivo de alunos nas turmas em que lecionam.

Esse cenário é muito desfavorável para a integração do professor com seus pares. A troca de experiências e de discussões acerca das dificuldades enfrentadas no ensino e aprendizagem exige do corpo docente tempo, negociação e tranquilidade. Lidar com essas tensões é difícil quando se está com a sensação de que o volume de trabalho e as exigências pelo cumprimento de prazos são inesgotáveis. Dessa forma, aspectos como a ausência de reflexão 
aprofundada sobre a atividade docente, a resistência a qualquer tipo de inovação e a dificuldade de compartilhar dilemas e dificuldades com o grupo docente, estão cada vez mais cristalizados entre os docentes.

Nessa perspectiva, concordamos com Lortie (1975), que aponta o individualismo como o agente responsável pelo desenvolvimento do conservadorismo, do imediatismo e do isolamento entre os docentes.

As relações interpessoais entre professores podem ocorrer em quatro perspectivas diferentes: individualismo já discutido, a colaboração, a colegialidade artificial, e a balcanização (HARGREAVES, 1999). Essas perspectivas têm razões históricas e, também, podem estar relacionadas ao ambiente escolar.

Segundo Hargreaves (1999), a colaboração acontece quando um grupo de professores estabelece objetivos comuns e, na intenção de atingir esses, negociam pontos de vista, apoiam-se mutuamente e investem seus recursos pessoais na empreitada, independentemente de facilidades ou estímulos externos ao grupo. Nesta perspectiva, o que estimula a manutenção do grupo é: o ímpeto de se atingirem os objetivos traçados coletivamente, o compartilhamento das soluções pensadas e das aprendizagens construídas por meio da experiência pessoal no grupo.

A colegialidade artificial seria uma forma de relacionamento em que os docentes são, de certa maneira, levados a se agrupar em torno de um objetivo almejado por alguém externo ao grupo, não sendo, portanto, uma opção dos docentes. Dessa forma, os professores são, de certa maneira, coagidos a se organizar em torno de um projeto coletivo, que poderá não representar os anseios dos docentes. Para garantir a manutenção do grupo, é preciso propiciar facilidades para a adesão dos professores, tais como: flexibilidade de horários, fornecimento de recursos materiais extras, entre outros.

A balcanização seria um processo de divisão do corpo docente da escola em grupos menores. Essa fragmentação pode ocorrer, por exemplo, em virtude de objetivos diferentes que determinados grupos menores podem ter em função dos segmentos em que atuam ou, mesmo, pela manutenção de espaços conquistados pelos docentes que atuam num dado segmento dentro da escola. Tal forma de relacionamento pode ser vista em escolas com modalidades diferentes de ensino. Nesse caso, é comum que os docentes de segmentos diferentes tenham horários diferentes e objetivos próprios do segmento em que atuam; essa situação dificulta a integração do corpo docente, que acaba, quase que invariavelmente, pensando e buscando resolver apenas os problemas específicos de seus respectivos segmentos.

\section{Benefícios da colaboração para o ensino}

Segundo Boavida e Ponte (2002), a colaboração é uma estratégia fundamental para enfrentar problemas de natureza complexa, como, por exemplo, a prática pedagógica. Nono e Mizukami (2001) argumentam que a colaboração pode favorecer o desenvolvimento da criticidade, da resolução de problemas e tomada de decisões.

Boavida e Ponte (2002) apontam que a colaboração oferece as seguintes vantagens em relação ao trabalho individual na concretização dos objetivos traçados: aumento do empenho em virtude da maior quantidade de pessoas envolvidas, mais recursos devido às trocas de 
Santos Júnior, J. B.; Marcondes, M. E. R.

experiências entre os colaboradores, propiciando mais segurança em mudanças e inovações, as interações favorecem os processos de reflexão, de aprendizagens mútuas e melhores condições para o enfrentamento de obstáculos e incertezas que possam surgir.

Faz-se necessário diferenciar os dois processos - colaboração e cooperação -, isto porque os dois termos, embora conceitualmente diferentes, costumam ser empregados como sinônimos. Muitos autores (BOAVIDA; PONTE, 2002; HARGREAVES, 1999; PONTE; SERRAZINA, 2003) descrevem que, de um modo geral, a concretização da colaboração se dá mediante alto grau de negociação, confiança, diálogo, empatia e interações não hierarquizadas. A cooperação é uma estratégia para realizar ou alcançar um objetivo ou meta, em que as relações tendem a se basear na posição hierárquica dos componentes do grupo. Nessa perspectiva, a colaboração pode ser entendida como uma filosofia e estilo de vida, enquanto a cooperação, um meio facilitador para se atingir um objetivo (PANITZ, 1996 apud TORRES; ALCANTARA; ESROM, 2004, p. 4).

\section{Metodologia}

Esta pesquisa foi realizada tendo como público-alvo um grupo de quatro professores (P1, P2, P3 e P4) da rede pública do Estado de São Paulo, todos atuantes na cidade de São Paulo. Esses professores possuem formação profissional. O Quadro 1 apresenta o perfil profissional e a experiência profissional de cada professor.

Quadro 1. Caracterização dos professores do grupo colaborativo

\begin{tabular}{|l|c|l|}
\hline Docente & Experiência profissional & \multicolumn{1}{|c|}{ Formação } \\
\hline P1 & 13 anos & Licenciatura em Química \\
\hline P2 & 22 anos & Licenciatura em Química e Química industrial \\
\hline P3 & 10 anos & Licenciatura em Química \\
\hline P4 & 11 anos & $\begin{array}{l}\text { Engenharia Química, licenciatura em Química e mestrado em } \\
\text { engenharia }\end{array}$ \\
\hline
\end{tabular}

Fonte: elaborado pelos autores.

A formação do grupo foi iniciada com um convite, aos professores, para participarem de um curso de formação continuada oferecido pela Secretaria de Educação do Estado de São Paulo, no segundo semestre de 2006. Esse curso foi realizado no Instituto de Química da Universidade de São Paulo. Sete professores se dispuseram a participar da formação do grupo colaborativo, sendo que apenas quatro participaram de todo o processo. Foi solicitado, a cada docente, que respondesse a um Inventário do Modelo Didático (IMD), cujo objetivo era o de identificar os modelos didáticos pessoais dos docentes - esse inventário foi respondido por todos antes do primeiro encontro. 
A etapa seguinte consistia na estruturação do grupo em torno de um objetivo comum: a construção de um plano coletivo para o ensino de três conceitos químicos escolhidos pelos componentes. O intuito dessa estratégia era privilegiar a escolha de conteúdos que realmente seriam tratados com os alunos, o que poderia favorecer um maior engajamento por parte do grupo, e a possibilidade futura de se verificar a contribuição dos encontros na prática desses professores.

Esse ciclo de reuniões foi estruturado tendo em vista iniciar ou fomentar quatro objetivos entre os professores: a reflexão sobre o seu conhecimento de Química; a reflexão sobre a sua prática pedagógica; a busca e a troca de experiências entre os professores do grupo; o aproveitamento dessas experiências no planejamento das aulas.

O projeto colaborativo foi organizado para que as dificuldades inerentes ao ensino de cada um, dos conceitos químicos escolhidos pelo grupo, pudessem ser problematizadas em um ciclo de três encontros. Como finalização das discussões sobre o conceito abordado, o grupo deveria elaborar conjuntamente um plano de ensino, incorporando ideias debatidas nos encontros. Depois de concluída essa etapa, o processo de elaboração do plano de ensino para o conceito químico era tido como finalizado.

Cada encontro teve duração de quatro horas, e era gravado em áudio e vídeo. Essa dinâmica só foi desfeita para a análise do último conceito, que, por motivo das agendas dos envolvidos, aconteceu em dois encontros.

Definidos os conceitos químicos que seriam abordados, o primeiro encontro enfocou a manifestação das ideias de cada professor sobre o seu ensino do conceito, explicitando seu plano de ensino. A seguir, os aspectos presentes nos planos de cada docente foram discutidos em uma roda de discussões.

No encontro seguinte, os professores se organizaram em duplas e elaboraram um novo plano incorporando as ideias apresentadas durante o último encontro. A seguir, esse plano de ensino foi apresentado e analisado novamente.

No terceiro encontro, os professores, agora organizados em um único grupo, laboraram um plano de ensino conjunto para o conceito discutido, tendo em mente que esse plano deveria ser exequível com os recursos e condições típicas de uma escola pública. Terminada essa etapa, o pesquisador solicitou ao grupo que refletisse sobre tudo o que havia sido apresentado e problematizado durante os três encontros, e que verificasse se o plano final continha os elementos considerados por todos como fundamentais para o ensino daquele conceito químico. Após essa última análise, o plano foi dado como terminado.

O papel do pesquisador no grupo sofreu alterações no decorrer do trabalho. Inicialmente, parecia que o grupo tinha o pesquisador como um agente externo, com interesses e função diferentes dos demais. Essa situação descrevia o estabelecimento da colegialidade artificial, e não da colaboração.

Para contornar esse problema, o pesquisador começou a participar ativamente das discussões como um dos membros do grupo. Como o pesquisador também lecionava Química em uma escola pública, portanto, estaria em condição de contribuir e compreender os problemas enfrentados pelos demais professores. De fato, essa mudança de postura do pesquisador consolidou a relação de colaboração entre o grupo.

Para estabelecer uma relação entre as reestruturações diagnosticadas nos modelos didáticos de cada docente e a sua efetiva participação no grupo colaborativo, foram utilizadas 
as ideias de Donald Winnicott (1975), e, também, o conceito de "convite docente" proposto por Franzoni (2007).

$\mathrm{Na}$ perspectiva analítica de Winnicott, quando um indivíduo vivencia a passagem de uma situação familiar para outra desconhecida, ocorre, simultaneamente, um processo de transição de uma fase chamada de ilusão (caracterizada por ser familiar e confortável para o sujeito) para uma fase de desilusão (impregnada de tensões e insegurança). Essa fase é necessária e permite ao indivíduo ações criativas em relação à nova realidade que o envolve (VILLANI; FRANZONI; VALADARES, 2008).

Winnicott (1975) propõe que essa transição de fases pode ser subsidiada por meio de "objetos transacionais", cuja função seria a de tornar a transição um processo mais suportável para a pessoa. Winnicott (1975), para definir o objeto transacional, utiliza o exemplo de um bebê no momento do desmame.

O bebê que é totalmente dependente e protegido por sua mãe, vive um processo de transição. Nesse momento, um brinquedo ou um cobertor podem ter a função de um objeto transacional, pois, à medida que o bebê vai brincando com eles, gradativamente vai desprendendo-se de sua mãe e habituando-se a sua nova realidade.

Franzoni (2007) faz uma analogia entre a experiência do desmame descrita anteriormente com uma experiência de aprendizagem. Segundo a pesquisadora, essa experiência surge quando a prática ou os conhecimentos do professor são colocados em xeque frente a um dilema ou dificuldade, e o docente investe no enfrentamento dessa situação.

Franzoni (2007) propõe que os professores podem ser subsidiados no enfrentamento das dificuldades descritas anteriormente por meio de "convites docentes". Esses convites têm função análoga ao objeto transacional proposto por Winnicott (1975). Nesta investigação, o grupo colaborativo assumiu essa função.

Nesta perspectiva, foi feito um paralelo entre as reestruturações diagnosticadas nos modelos didáticos dos professores e a sua participação no grupo colaborativo. Essa participação consistia de dois aspectos: a aceitação e o investimento pessoal do docente no enfrentamento das dificuldades, e a adesão do docente à colaboração como recurso para auxiliá-lo e enfrentar essas dificuldades.

O elemento desencadeador desse processo era a atitude do docente em aceitar que possuía dificuldades relacionadas ao ensino do conceito e, a partir daí, enfrentá-las. Por essa razão, ele forma a base da pirâmide. A aceitação do grupo tem a ver com a admissão de que o professor precisa de ajuda (colaboração) para enfrentar essa situação.

A participação no grupo envolve engajamento pessoal em torno das atividades realizadas pelo grupo. Wenger (1998) aponta que aprendizagens em comunidades são diretamente proporcionais à participação do indivíduo nessa comunidade. A reestruturação do modelo didático do docente seria o produto desse processo. Dessa forma, o processo de reestruturação do modelo didático do docente pode ser esquematizado pela Figura 1. 
Grupos colaborativos como ferramenta ...

Figura 1. Esquematização do processo de reestruturação do modelo didático do professor

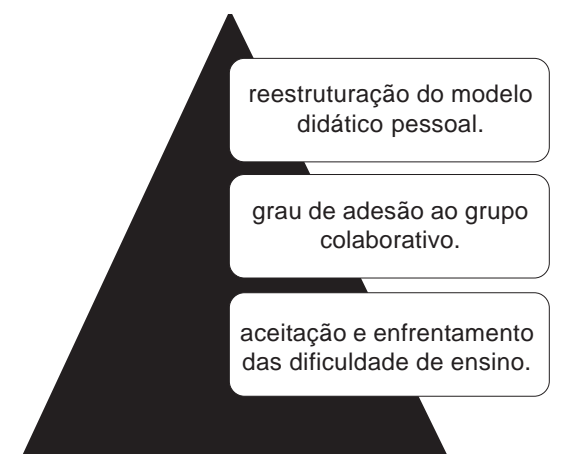

Fonte: elaborada pelos autores.

\section{O inventário do modelo didático do professor (IMD)}

Foi construído um instrumento (Anexo A) que consiste de uma pergunta-chave correspondente a cada uma das dimensões didáticas estudadas por García Pérez (2000).

Para cada uma delas, correspondiam quatro proposições características de cada um dos modelos didáticos propostos. O professor deveria atribuir um valor para cada proposição, seguindo o critério: 0 , completa rejeição; 3 completa aceitação; os valores 1 e 2 seriam intermediários entre a rejeição e a aceitação).

Esse questionário foi aplicado, inicialmente, a alunos da graduação e pós-graduação em ensino de Química, com o intuito de verificar a sua aplicabilidade em pesquisa, e verificar se as proposições caracterizavam os modelos didáticos correspondentes. Feitos os ajustes necessários, esse instrumento foi aplicado a um grupo de professores da Rede Pública, visando estudar se seria capaz de permitir ao pesquisador interpretar e diagnosticar modelos didáticos pessoais em professores.

Os modelos didáticos pessoais foram construídos a partir das aceitações das características declaradas pelos professores. Foi arbitrado que, sempre que o docente atribuísse os valores 2 ou 3 para uma dada característica, ele estaria aceitando-a na composição do seu respectivo modelo didático pessoal.

\section{Resultados}

De acordo com os valores atribuídos pelos docentes, para cada proposição que caracterizava um dos modelos didáticos propostos por García Pérez (2000) no IMD, foi elaborado um quadro que permitia visualizar os modelos didáticos pessoais pré e pós-trabalho colaborativo. Foi arbitrado nessa investigação que sempre que o professor atribuísse os valores 2 ou 3 para a proposição, essa seria considerada como aceita pelo docente e faria parte do modelo didático pessoal desse docente. 
Santos Júnior, J. B.; Marcondes, M. E. R.

Nesse esquema, as características aceitas pelos professores numa dada dimensão foram indicadas em cinza e estão representadas nos Quadros 2 a 5, para cada um dos docentes. Nesses quadros, o modelo didático tradicional é representado pela letra T; a letra $\mathrm{C}$ representa o modelo didático tecnicista; A letra E, o modelo espontaneísta, e o modelo didático alternativo é representado pela letra A. A esquematização dos processos de reestruturação de cada professor é representada nas Figuras 2 a 5. Foram inseridos, nesses esquemas, exemplos de falas dos professores, para corroborar a análise dos pesquisadores.

Quadro 2. Modelos didáticos pessoais pré e pós-grupo colaborativo de P1

\begin{tabular}{|c|c|c|c|c|c|c|c|c|c|c|c|c|c|c|c|c|c|c|c|c|}
\hline \multirow[b]{2}{*}{ Modelo didático } & \multicolumn{4}{|c|}{ Dimensão 1} & \multicolumn{4}{|c|}{ Dimensão 2} & \multicolumn{4}{|c|}{ Dimensão 3} & \multicolumn{4}{|c|}{ Dimensão 4} & \multicolumn{4}{|c|}{ Dimensão 5} \\
\hline & $\mathrm{T}$ & C & $E$ & A & $\mathrm{T}$ & C & $E$ & A & $\mathrm{T}$ & C & $E$ & A & & C & $E$ & A & & C & $E$ & $A$ \\
\hline Pré-grupo & & & & & & & & & & & & & & & & & & & & \\
\hline Pós-grupo & & & & & & & & & & & & & & & & & & & & \\
\hline
\end{tabular}

Fonte: elaborado pelos autores.

Figura 2. Esquematização do processo de reestruturação do modelo didático de P1

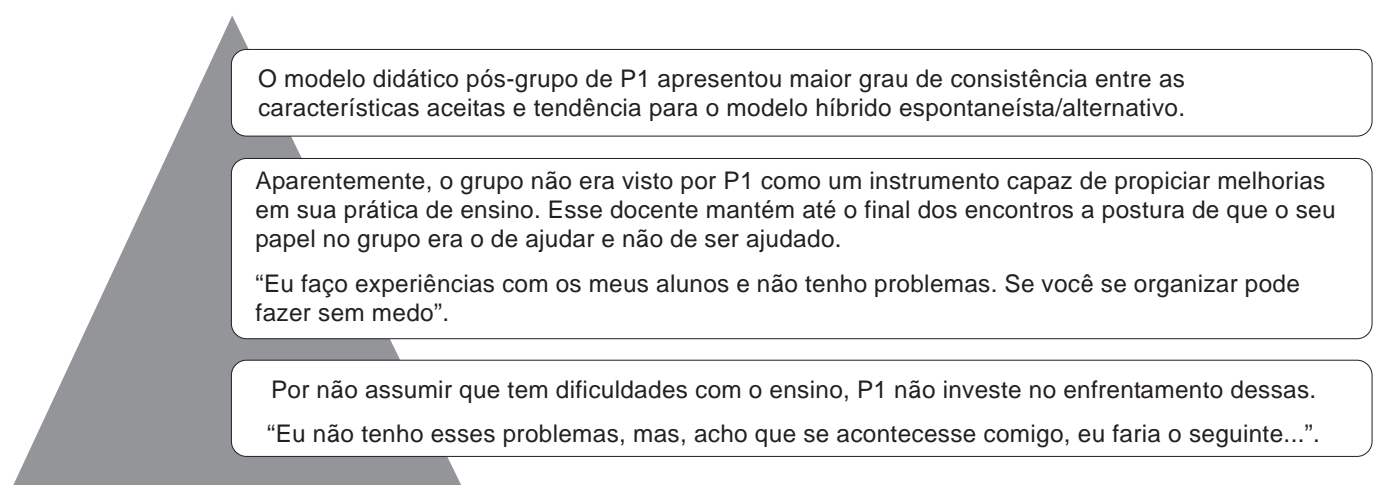

Fonte: elaborada pelos autores.

Quadro 3. Modelos didáticos pessoais pré e pós-grupo colaborativo de P2

\begin{tabular}{|c|c|c|c|c|c|c|c|c|c|c|c|c|c|c|c|c|c|c|c|c|}
\hline \multirow[b]{2}{*}{ Modelo didático } & \multicolumn{4}{|c|}{ Dimensão 1} & \multicolumn{4}{|c|}{ Dimensão 2} & \multicolumn{4}{|c|}{ Dimensão 3} & \multicolumn{4}{|c|}{ Dimensão 4} & \multicolumn{4}{|c|}{ Dimensão 5} \\
\hline & $\mathrm{T}$ & C & $E$ & A & $\mathrm{T}$ & $C$ & $E$ & A & $\mathrm{T}$ & C & $E$ & A & & C & $E$ & A & & C & $E$ & A \\
\hline \multicolumn{21}{|l|}{ Pré-grupo } \\
\hline Pós-grupo & & & & & & & & & & & & & & & & & & & & \\
\hline
\end{tabular}

Fonte: elaborado pelos autores. 
Figura 3. Esquematização do processo de reestruturação do modelo didático de P2

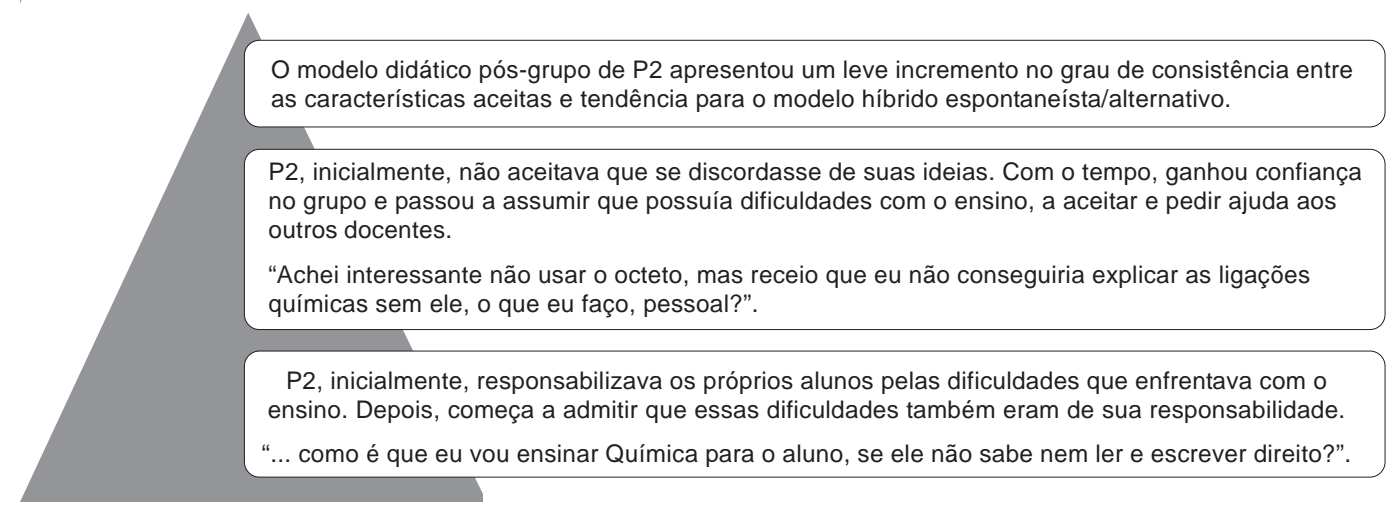

Fonte: elaborada pelos autores.

Quadro 4. Modelos didáticos pessoais pré e pós-grupo colaborativo de P3

\begin{tabular}{|l|l|l|l|l|l|l|l|l|l|l|l|l|l|l|l|l|l|l|l|l|l|l|l|l|}
\hline & \multicolumn{3}{|c|}{ Dimensão 1 } & \multicolumn{3}{|c|}{ Dimensão 2 } & \multicolumn{4}{|c|}{ Dimensão 3 } & & \multicolumn{3}{c|}{ Dimensão 4 } & & \multicolumn{3}{c|}{ Dimensão 5 } \\
\hline Modelo didático & T & C & E & A & & T & C & E & A & & T & C & E & A & & T & C & E & A & & T & C & E & A \\
\hline Pré-grupo & & & & & & & & & & & & & & & & & & & & & & \\
\hline Pós-grupo & & & & & & & & & & & & & & & & & & & & & & & & \\
\hline
\end{tabular}

Fonte: elaborado pelos autores.

Figura 4. Esquematização do processo de reestruturação do modelo didático de P3

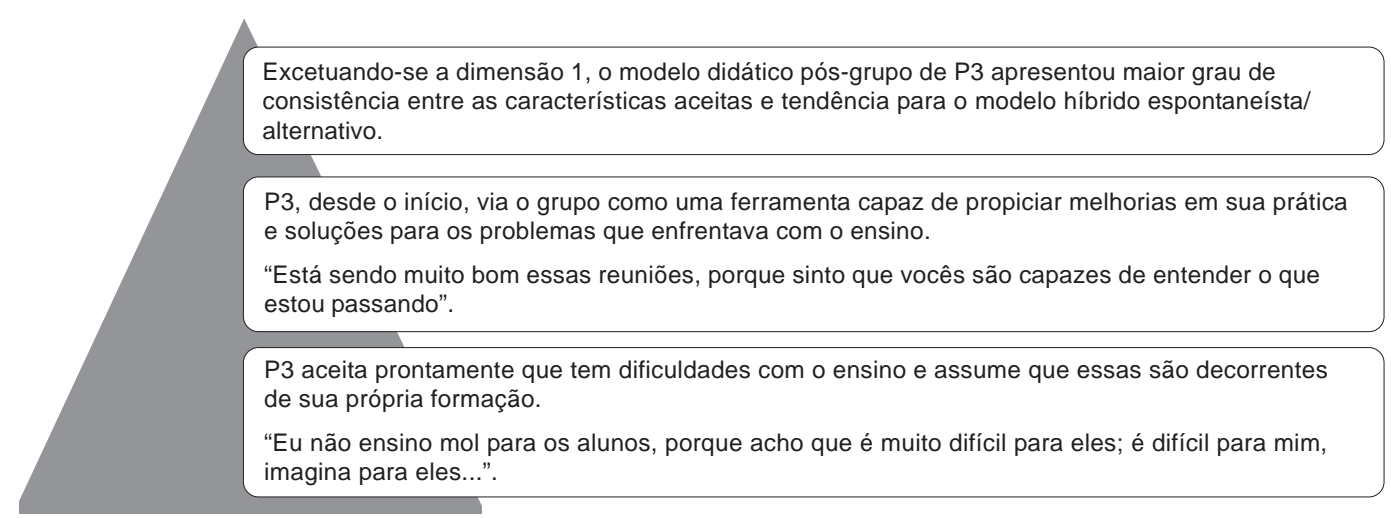

Fonte: elaborada pelos autores. 
Santos Júnior, J. B.; Marcondes, M. E. R.

Quadro 5. Modelos didáticos pessoais pré e pós-grupo colaborativo de P4

\begin{tabular}{|l|l|l|l|l|l|l|l|l|l|l|l|l|l|l|l|l|l|l|l|l|l|l|l|l|}
\hline & \multicolumn{3}{|c|}{ Dimensão 1 } & \multicolumn{3}{|c|}{ Dimensão 2 } & \multicolumn{4}{|c|}{ Dimensão 3 } & & \multicolumn{3}{c|}{ Dimensão 4 } & & \multicolumn{3}{c|}{ Dimensão 5 } \\
\hline Modelo didático & T & C & E & A & & T & C & E & A & & T & C & E & A & & T & C & E & A & & T & C & E & A \\
\hline Pré-grupo & & & & & & & & & & & & & & & & & & & & & & \\
\hline Pós-grupo & & & & & & & & & & & & & & & & & & & & & & & \\
\hline
\end{tabular}

Fonte: elaborado pelos autores.

Figura 5. Esquematização do processo de reestruturação do modelo didático de P4

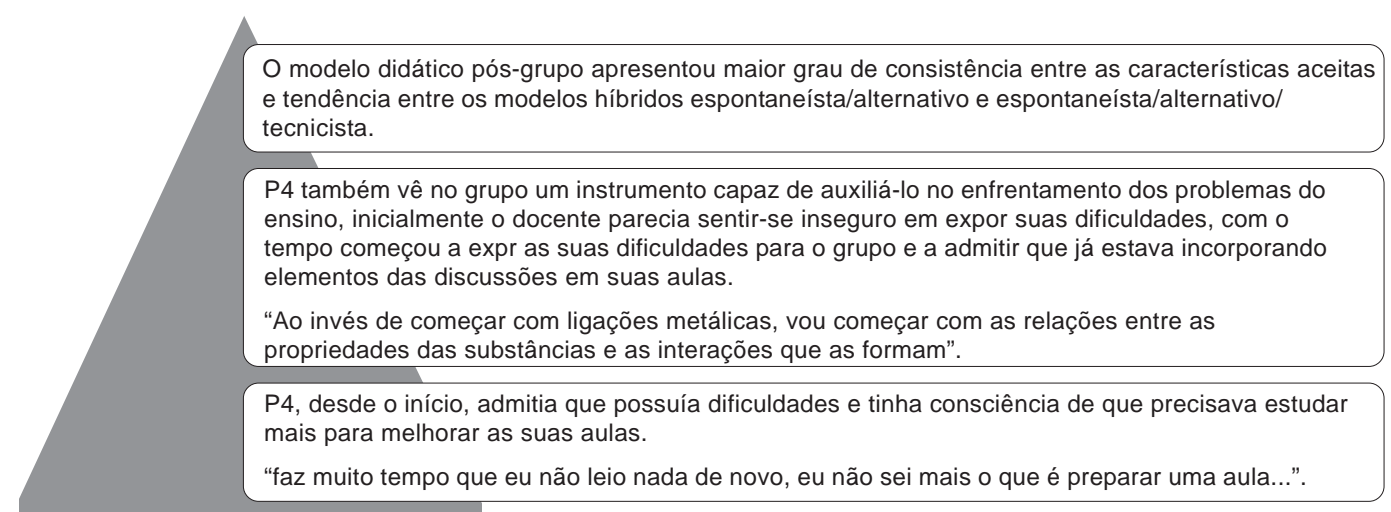

Fonte: elaborada pelos autores.

\section{Análise}

Considerando-se os valores atribuídos pelo grupo para as proposições que caracterizavam cada um dos modelos didáticos propostos por García Pérez (2000), foi possível perceber que os docentes tinham afinidade com características de vários dos modelos propostos. Essa multiplicidade pode ser entendida como uma indefinição em relação aos pressupostos que alicerçam a concepção desses modelos, uma vez que os professores valorizavam proposições antagônicas em uma mesma dimensão analisada, fato que pode revelar uma necessidade de amadurecimento profissional ou um momento de transição do docente (GUIMARÃES; ECHEVERRÍA; MORAES, 2006).

Nessa perspectiva, no questionário inicial, P1, P2, P3 e P4 manifestaram, com suas respostas, afinidade pelas características dos quatro modelos didáticos diferentes, dentro de uma mesma dimensão. Condição que sofreu alterações ao final das reuniões e que puderam ser apontadas com base nas declarações dos docentes no IMD pós-grupo.

É perceptível que as discussões contribuíram para que P1 pudesse refletir acerca de suas ideias sobre o ensino e a aprendizagem. Se, no IMD pré-grupo, esse docente havia decla- 
rado aceitar características antagônicas dos modelos didáticos propostos, dentro de uma mesma dimensão analisada; tal fato, não é observado no IMD pós-grupo, onde é notado que as características aceitas pelo docente possuem maior grau de convergência. O que permite inferir que o modelo didático pessoal de P1 possui maior grau de consistência. De acordo com as declarações dadas pelo professor, é possível diagnosticar um modelo didático híbrido do tipo espontaneísta/alternativo.

Embora pareça ser evidente a contribuição do grupo sobre o processo de reestruturação do modelo didático pessoal de P1, algumas considerações sobre a participação desse docente no grupo precisam ser feitas. P1 não faltou a nenhuma das reuniões - fato que indica que essas reuniões tinham algum tipo significado para o docente, ainda mais, considerando-se que esses encontros aconteciam aos sábados e sem qualquer tipo de apoio ou benefício para os professores. Além de assíduo, esse professor era muito participativo nas discussões e tarefas propostas. Chamava a atenção o fato de que P1 não se sentia a vontade para explicitar aspectos de sua prática pedagógica que pudessem levar à conclusão de que ele poderia ter problemas com o ensino.

De fato, todas as manifestações de P1 que evocavam a sua prática pedagógica diziam respeito a experiências exitosas, nunca a qualquer tipo de insucesso. Talvez, essa postura tenha sido um empecilho para um processo de reestruturação mais abrangente. No grupo aqui constituído, as dificuldades explicitadas pelos professores eram problematizadas, esse processo forçava todos a se debruçarem sobre suas crenças, ideias, experiências pessoais e conhecimentos profissionais. Trata-se de um longo percurso que, ao ser trilhado por cada docente, foi fomentando uma reflexão mais aprofundada (que nem sempre acontece na rotina escolar). P1, por não ter exposto suas dificuldades, pode ter aproveitado menos do trabalho colaborativo.

P2 parecia ser, no início, o professor que apresentava uma visão do processo de ensino e aprendizagem mais consistente do grupo, pois, apenas em uma dimensão, manifestou a aceitação de características dos quatro modelos concomitantemente; nas outras dimensões, manifestou características de, no máximo, dois dos modelos didáticos propostos, as quais não eram antagônicas, pois os pressupostos desses modelos colocavam o aluno como centro do processo de ensino e aprendizagem. Seria possível propor que o professor possuía, baseado no IMD pré-grupo, uma certa tendência para modelo didático pessoal híbrido do tipo alternativo/espontaneísta, que consolidou-se nas declarações dadas pelo docente no IMD pós-grupo.

O termo consistência foi utilizado aqui no sentido de que o modelo didático pessoal do docente encerra características com uma mesma orientação didática, neste caso, transmissão cultural ou construtivista. A aceitação de características antagônicas pode permitir a inferência de uma visão do processo de ensino e aprendizagem fragmentada e sem coesão.

Em relação ao grupo, esse professor tinha um comportamento considerado por todos como difícil. O docente não aceitava críticas e nem que se discordasse de suas ideias. Quando isso aconteceu, P2 chegou a ser agressivo com os outros professores. Outra característica de P2 era que, quando assumia as suas dificuldades, ele responsabilizava terceiros por essas (alunos, gestores da escola, o corpo docente). No início dos trabalhos, esse comportamento gerou preocupação no pesquisador. P2, a exemplo de P1, não perdeu nenhum dos encontros e era bastante participativo. Com o passar do tempo, P2 passou a aceitar críticas e assumir sua parcela de responsabilidade sobre as suas dificuldades com o ensino. Essa mudança de comportamento ficou evidente entre o terceiro e quarto encontro. É possível inferir que o compor- 
tamento inicial do docente, que dificultava sua integração com o grupo, possa ter sido um empecilho no sentido de um processo de reestruturação mais abrangente.

As reestruturações nos modelos didáticos pessoais mais abrangentes foram diagnosticadas em P3 e P4. Esses docentes deram evidências, durante os encontros, de que, de fato, o grupo estaria subsidiando mudanças em suas práticas e concepções.

No caso de P3, foi percebido que essa reestruturação foi mais marcante nas dimensões 2 e 3, que diziam respeito ao conteúdo escolar e ao papel das ideias e interesses dos alunos, respectivamente. Uma evidência de como o trabalho colaborativo fomentou mudanças no pensamento desse professor, pôde ser identificada nos encontros onde se problematizavam as dificuldades de ensino do conceito de quantidade de matéria. P3, que no primeiro encontro assumiu não abordar esse conceito por não dominá-lo e, também, por considerá-lo inútil para os alunos, após o fechamento das reuniões no terceiro encontro, argumentou que havia mudado de ideia, que esse conceito era importante para futuras aprendizagens em Química e que, para o próximo ano letivo, iria se preparar para ensiná-lo para os alunos.

Essa era uma característica marcante em P3. Este parecia ser o docente com a maior preocupação com a formação cultural de seus alunos. Por vezes, o docente afirmou que não adiantava um aluno aprender um dado conteúdo científico, se o aluno iria enfrentar muitas situações em que esse conteúdo não seria utilizado. P3 parecia ter uma visão de ensino em que a Ciência ocupava um lugar muito distante da realidade dos alunos. Em virtude dessa visão de ensino de P3, o pesquisador passou a incorporar, nas discussões com o grupo, aspectos do ensino na perspectiva CTS (Ciência, Tecnologia e Sociedade). Essa estratégia parece ter surtido efeito em P3, que percebeu que os conhecimentos científicos devem fazer parte da formação do educando.

P4 também dava evidências de que o trabalho do grupo estava sendo importante para ele. Além de admitir que já estava incorporando ideias do grupo em suas aulas, teve uma mudança de postura marcante durante os encontros. Esse professor era o que menos falava nas reuniões, contudo, era o que mais fazia anotações e prestava muita atenção ao que era dito pelos outros docentes. De fato, P4 só se manifestava quando uma pergunta era feita diretamente a ele, caso contrário, ficava fazendo suas anotações. Essa atitude foi entendida pelos pesquisadores como uma característica pessoal de P4, que deixava transparecer ser muito tímido e inseguro. Durante os encontros, o docente parece ter ganhado confiança em si mesmo e, também, nos outros professores, fato que parece ter contribuído para que ele começasse a se manifestar abertamente.

Esse docente foi o único que admitiu abertamente que já estava incorporando ideias do grupo em suas aulas. E citou, como exemplo, o ensino de ligações químicas. P4 sempre seguiu a ordem indicada na maioria dos livros didáticos: primeiro, se deve abordar as ligações metálicas, depois, a iônica e, por fim, a covalente. O docente optou por iniciar o estudo das ligações químicas apresentando, aos alunos, as diferenças entre as propriedades dos compostos iônicos e covalentes, e relacioná-las com o tipo de ligação presente em cada tipo de composto, e, a partir daí, enfocar as características dessas ligações, que condizia com o plano de ensino elaborado pelo grupo para o ensino desse conceito químico. 


\section{Conclusões e considerações finais}

É perceptível que o trabalho colaborativo se confirmou como um espaço de aprendizagem, reflexão e reestruturação de ideias e concepções. Todos os docentes apresentaram um ganho de coerência em relação às suas visões anteriores à formação do grupo. Outro ponto a se destacar é que, embora não fosse o intuito do grupo, observa-se uma tendência alinhada à visão construtivista do processo de ensino e aprendizagem, esta constatação está fundamentada nas aceitações dos modelos didáticos espontaneísta e alternativo, declaradas pelos docentes no IMD. Esta tendência não foi diagnosticada nos modelos didáticos pré-grupo.

É importante ressaltar que os ganhos obtidos pelos docentes que participaram desse projeto colaborativo, não se restringiram apenas aos conhecimentos específicos para o exercício da docência. Ao participar do grupo, cada docente desenvolveu-se no que diz respeito às relações pessoais, como: maior tolerância, maior capacidade em lidar com tensões, ponderação em administrar objetivos individuais e coletivos. Tais capacidades são, sem dúvida, importantes para os profissionais que exercem atividades sociais, como a docência, por exemplo.

Também foi perceptível o desenvolvimento da argumentação; essa competência pode não ser bem desenvolvida nas licenciaturas e é outro atributo importante para o professor.

Em relação aos modelos didáticos, dada a sua natureza complexa e idiossincrática, esses podem ser um importante subsídio a ser explorado na pesquisa em Ensino e até em cursos de formação contínua. Esses modelos podem, por exemplo, ser utilizados em situações em que o docente precise refletir sobre seus conhecimentos, práticas e concepções. Essas situações podem fomentar uma experiência metacognitiva no professor, instigando-o a reavaliar seus pontos de vista e ações didáticas.

Os resultados obtidos nesse trabalho corroboram as constatações detectadas por outros trabalhos onde é apontado que, entre os modelos didáticos propostos por García Pérez (2000), não existe um que, predominantemente, represente o fazer pedagógico dos professores; e, também, de que os docentes valorizam características de vários dos modelos didáticos propostos para construir um modelo didático próprio chamado de eclético (GUIMARÃES; ECHEVERRÍA; MORAES, 2006), ou híbrido (SANTOS JR. e MARCONDES, 2008).

Os modelos didáticos pessoais ecléticos ou híbridos (GUIMARÃES, ECHEVERRÍA e MORAES, 2006; SANTOS JR.; MARCONDES, 2008), por serem formados pela sobreposição de características de modelos diferentes e, em alguns casos antagônicos, podem ser um indicativo de que, por um lado, os docentes precisem, de fato, refletir sobre suas ideias, a fim de perceber suas inconsistências e incoerências. Por outro lado, esses modelos podem indicar um conflito entre aquilo que o docente acredita e o que, de fato, consegue fazer, considerando-se que o contexto escolar em que o professor atua tem grande influência no seu modelo didático. De fato, é preciso lembrar que essas representações são transitórias (CHROBAK, 2006), não podendo ser entendidas como uma estrutura estática e acabada.

As discussões parecem ter sido mais proveitosas no sentido de os professores perceberem as inconsistências existentes em suas concepções do que, propriamente, explicitar as diferenças entre um e outro modelo didático. Para isso, talvez fosse necessário um projeto com maior prazo.

Finalizando, ficou evidente, nesse trabalho, que o grupo foi importante no sentido de propiciar a reflexão, de todos os docentes, das suas concepções sobre o processo de ensino e 
Santos Júnior, J. B.; Marcondes, M. E. R.

aprendizagem. Apesar dessa certeza, é preciso salientar que, em um projeto colaborativo, os resultados obtidos no grupo constituído nessa pesquisa estavam vinculados ao grau de engajamento de cada participante no grupo. Essa sincronia remete às ideias sobre aprendizagem em comunidades de prática (LAVE; WENGER, 1991).

\section{Referências}

ABIB, M. L. V. S. A contribuição da prática de ensino na formação inicial de professores de física. In: ROSA, D. E. G.; SOUZA, V. C. Didáticas e práticas de ensino: interfaces com diferentes saberes e lugares formativos. Rio de Janeiro: DP\&A, 2002. p. 188-204.

ALMEIDA, M. I. Apontamentos a respeito da formação de professores. In: BARBOSA, R. L. L. Formação de educadores: artes e técnicas-ciências e políticas. São Paulo: Editora Unesp, 2006. p. 177-188.

BEACH, R.; PEARSON, D. E. Changes in preservice teachers' perceptions of conflicts and tensions. Teaching and Teacher Education, Amsterdam, v. 14, n. 3, p. 337-351, 1998.

BOAVIDA, A. M.; PONTE, J. P. Investigação colaborativa: potencialidades e problemas. In: GTI (Org). Reflectir e investigar sobre a prática profissional. Lisboa: APM, 2002. p. 43-55.

CHROBAK, R. Mapas conceituales y modelos didacticos de professors de química. In: CONGRESO INTERNACIONAL SOBRE MAPAS CONCEPTUALES, 2., 2006, San José. Actas... Disponível em: <http://cmc.ihmc.us/cmc2006Papers/cmc2006-p215.pdf>. Acesso em: 31 jul. 2013.

FRANZONI, M. A Teoria psicanalítica de Winnicott na formação de professores. In: FRANZONI, M.; ALLEVATO, N. S. G. (Org.). Reflexões sobre a formação de professores e o ensino de ciências e matemática. Ijui: Alinea, 2007. p. 21-40.

FREITAS, D.; VILLANI, A. Formação de professores de ciências: um desafio sem limites. Investigações em Ensino de Ciências, Porto Alegre, v. 7, n. 3, p. 215-230, 2002.

FULLAN, M.; HARGREAVES, A. A escola como organização aprendente. Porto Alegre: Artmed, 1998.

FURIÓ, C.; CARNICER, J. El desarollo profesional del profesor de ciencias mediante tutorías de grupos cooperativos: estudio de ocho casos. Enseñanza de las Ciencias, Barcelona, v. 20, n. 1, p. 47-73, 2002.

GARCIA, C. M. Formación del profesorado para el cambio educativo. Barcelona: EUB, 1995.

GARCÍA PÉREZ, F. F. Los modelos didácticos como instrumento de análisis y de intervención en la realidad educativa. Revista Bibliográfica de Geografía y Ciencias Sociales, Barcelona, n. 207, p. 21-34, 2000. 
Grupos colaborativos como ferramenta ...

GENÉ, A.; GIL, D. Tres principios básicos en la formación del professorado. Andecha Pedagógica, Gijón, n. 18, p. 28-30, 1987.

GIL-PÉREZ, D.; CARVALHO, A. M. P. Formação de professores de ciências: tendências e inovações. São Paulo: Cortez, 1995.

GUIMARÃES, M. A. G.; ECHEVERrÍA, A. R.; MORAES, J. I. Modelos didáticos no discurso de professores de ciências. Revista Eletrônica de Investigação em Ensino de Ciências, v. 3, n. 11, 2006.

HARGREAVES, A. Profesorado, cultura y postmodernidad. Madrid: Morata, 1999.

IMBERNÓN, F. La formación y el desarrollo profesional del profesorado hacia una nueva cultura profesional. Barcelona: Grao, 1998.

LACERDA, M. P. Quando falam as professoras alfabetizadoras. Rio de Janeiro: DP\&A, 2002.

LAVE, J.; WENGER, E. Situated learning: legitimate peripheral participation. Cambridge: Cambridge University Press, 1991.

LIBÂNEO, J. C.; PIMENTA, S. G. Formação de profissionais da educação: visão crítica e perspectiva de mudança. Educação \& Sociedade, Campinas, v. 20, n. 68, p. 239-277, 1999.

LORTIE, D. School teachers: a sociological study. Chicago: University of Chicago Press, 1975.

MELLADO, V. J. Cambio didáctico del profesorado de ciencias experimentales y filosofía de la ciencia. Ensenãnza de las Ciencias, Barcelona, v. 21, n. 3, p. 343-358, 2003.

NONO, M. A.; MIZUKAMI, M. G. N. Aprendendo a ensinar: futuras professoras das séries iniciais do ensino fundamental e casos de ensino. In: REUNIÃO ANUAL DA ANPED, 24., 2001, Caxambu. Anais... Disponível em: <http://www.anped.org.br/ reunioes/24/tp.htm>. Acesso em: 30 jul. 2013.

PIMENTA, S. G. Apresentação. In: LEITE, Y. U. F.; GHEDIN, E.; ALMEIDA, M. I. Formação de professores: caminhos e descaminhos da prática. Brasilia: Líber, 2008. p. $9-11$.

PONTE, J. P.; SERRAZINA, L. Professores e formadores investigam a sua própria prática: o papel da colaboração. Zetetiké, Campinas, v. 11, n. 20, p. 51-84, 2003.

PORLÁN ARIZA, R.; RIVERO GARCÍA, A.; MARTÍN DEL POZO, R. Conocimiento profesional y epistemología de los profesores I: teoría, métodos e instrumentos.

Enseñanza de las Ciencias, Barcelona, v. 15, n. 2, p. 155-171, 1997.

Conocimiento profesional y epistemológico de los profesores, II: estudios empíricos y conclusiones, Enseñanza de las Ciencias, Barcelona, v. 16, n. 2, p. 271-288, 1998. 
Santos Júnior, J. B.; Marcondes, M. E. R.

PROPOSTAS curriculares de ciências. In: BARRETTO, E. S. S. (Coord.). As propostas curriculares oficiais: análise das propostas curriculares dos estados e de alguns municípios das capitais para o ensino fundamental. São Paulo: Fundação Carlos Chagas, 1995. p. 59-84.

SACRISTÁN, J. G. Poderes instáveis em educação. Porto Alegre: Artes Médicas, 1999.

SADALLA, A. M. F. A. et al. Partilhando formação, prática e dilemas: uma contribuição ao desenvolvimento docente. Psicologia Escolar e Educacional, Campinas, v. 9, n. 1, p.7186, 2005.

SANTOS JR., J. B.; MARCONDES, M. E. R. Um estudo sobre os modelos didáticos de um grupo de professores de química. In: ENCONTRO NACIONAL DE ENSINO DE QUÍMICA, 14., 2008, Curitiba. Anais... Disponível em: <http://www.quimica.ufpr.br/ eduquim/eneq2008/resumos/R0381-1.pdf >. Acesso em: 08 abr. 2009.

SCHNETZLER, R. P. Prática de ensino nas ciências naturais: desafios atuais e contribuições de pesquisa. In: ROSA, D. E. G; SOUZA, V. C. Didáticas e práticas de ensino: interfaces com diferentes saberes e lugares formativos. Rio de Janeiro: DP\&A, 2002. p. 205-222.

A pesquisa no ensino de química e a importância da Química Nova na Escola. Química Nova na Escola, São Paulo, n. 20, p. 49-54, 2004.

TORRES, P. L.; ALCANTARA, P. R.; ESROM, A. F. I. Grupos de consenso: uma proposta de aprendizagem colaborativa para o processo de ensino-aprendizagem. Diálogo Educacional, Curitiba, v. 13, n. 4, p.129-145, 2004.

VÁZQUEZ BERNAL, B.; JIMÉNEZ PÉREZ, R.; MELLADO JIMÉNEZ, V. El desarrollo profesional del profesorado de ciencias como integración de la reflexión y la práctica: la hipótesis de la complejidad. Revista Eureka sobre Enseñanza y Divulgación de las Ciencias, Cádiz, v. 4, n. 3, p. 372-393, 2007.

VILLANI, A.; FRANZONI, M.; VALADARES, J. M. Desenvolvimento de um grupo de licenciandos numa disciplina de prática de ensino de física e biologia. Investigações em Ensino de Ciências, Porto Alegre, v. 13, n. 2, p. 143-168, 2008.

VYGOTSKY, L. S. A formação social da mente. São Paulo: Martins Fontes, 1998.

WARTHA, E. J.; GRAMACHO, R. S. Abordagem problematizadora na formação docente. In: REUNIÃO ANUAL DA SBQ, 30., 2007, Águas de Lindoia. Anais... Disponível em: <http://www.sbq.org.br/30ra/Workshop\%20UESC.pdf>. Acesso em: 13 jul. 2010.

WENGER, E. Communities of practice: learning, meaning and identity. Cambridge: Cambridge University Press, 1998.

WINNICOT'T, D. W. O brincar e a realidade. Rio de Janeiro, Imago, 1975. 
Anexo A. Inventário modelo didático

Prezado Professor,

De acordo com a sua visão de ensino e de aprendizagem, atribua, para cada uma das proposições apresentadas, um valor. Sendo o valor zero para aquela(s) proposição(ões) que você refuta e três para aquela(s) com a(as) qual(ais) você concorda plenamente. Utilize o valor 1 para as proposições que você refuta parcialmente e 2 para as que você aceita parcialmente.

\begin{tabular}{|c|c|}
\hline Dimensão 1 - Qual é o meu principal objetivo ao ensinar química? & Valor \\
\hline \multicolumn{2}{|l|}{ Para que meu aluno possa se tornar um indivíduo dotado da cultura vigente. } \\
\hline \multicolumn{2}{|l|}{$\begin{array}{l}\text { Para que meu aluno tenha uma formação eficiente e moderna, ou seja, esteja inserido no mundo tecnológico no } \\
\text { qual todos nós precisamos conviver. }\end{array}$} \\
\hline \multicolumn{2}{|l|}{ Para que meu aluno se torne um cidadão crítico, ético e atuante no mundo em que vive. } \\
\hline \multicolumn{2}{|l|}{$\begin{array}{l}\text { Para que meu aluno possa enriquecer progressivamente seus conhecimentos e vá aos poucos conseguindo } \\
\text { fazer leituras cada vez mais complexas do mundo em que vive. }\end{array}$} \\
\hline \multicolumn{2}{|l|}{ Dimensão 2 - Que conteúdo de química eu devo ensinar aos meus alunos? } \\
\hline \multicolumn{2}{|l|}{ Uma síntese dos conceitos químicos mais importantes. } \\
\hline \multicolumn{2}{|l|}{$\begin{array}{l}\text { Uma síntese dos conceitos químicos mais importantes, combinados com aplicações tecnológicas desses } \\
\text { conceitos. }\end{array}$} \\
\hline \multicolumn{2}{|l|}{ Conceitos químicos presentes nos fenômenos que se apresentam no cotidiano do aluno. } \\
\hline \multicolumn{2}{|l|}{ Conhecimentos que permitam a integração nos níveis científico, social, histórico e ambiental. } \\
\hline \multicolumn{2}{|l|}{$\begin{array}{c}\text { Dimensão } 3 \text { - Qual é a contribuição das concepções e interesses do meu aluno em relação à minha } \\
\text { seleção dos conteúdos para ensinar meus alunos? }\end{array}$} \\
\hline \multicolumn{2}{|l|}{$\begin{array}{l}\text { O fundamental para a escolha dos conteúdos não é o interesse ou as concepções do aluno, e sim a capacidade } \\
\text { profissional do professor de escolher os conteúdos adequados para o ensino. }\end{array}$} \\
\hline \multicolumn{2}{|l|}{$\begin{array}{l}\text { Os interesses não precisam ser considerados, as concepções sim. Caso essas concepções sejam erradas } \\
\text { devem, com o ensino, ser substituídas, pelo aluno, por concepções mais próximas das científicas. }\end{array}$} \\
\hline \multicolumn{2}{|l|}{$\begin{array}{l}\text { As concepções não precisam ser consideradas, os interesses sim, pois, dessa forma, o estudo de química pode } \\
\text { ser mais atraente e significativo para o aluno. }\end{array}$} \\
\hline \multicolumn{2}{|l|}{ As concepções e os interesses devem nortear a escolha dos conteúdos que irão ser trabalhados. } \\
\hline \multicolumn{2}{|l|}{ Dimensão 4 - Como devo ensinar química aos meus alunos? } \\
\hline \multicolumn{2}{|l|}{$\begin{array}{l}\text { Como professor, devo estar apto a transmitir conhecimento ao meu aluno e manter uma ordem mínima necessária } \\
\text { para que seja possível o trabalho; o aluno, por sua vez, se fizer a sua parte, ou seja, prestar atenção às aulas, } \\
\text { fizer as atividades e se esforçar um pouco, poderá aprender química com sucesso. }\end{array}$} \\
\hline \multicolumn{2}{|l|}{$\begin{array}{l}\text { Como professor, devo combinar aulas expositivas com aulas práticas, usando todos os recursos didáticos de } \\
\text { que disponho, e atuar dentro da sala como um administrador das atividades; o aluno, por sua vez, deve fazer as } \\
\text { atividades propostas. }\end{array}$} \\
\hline \multicolumn{2}{|l|}{$\begin{array}{l}\text { Como professor, devo propor atividades que estimulem a capacidade de meu aluno de analisar, julgar, criticar e } \\
\text { exercer a sua cidadania, além, é claro, de aprender química; devo atuar dentro da sala como um coordenador; } \\
\text { o aluno é o centro do processo de ensino-aprendizagem. }\end{array}$} \\
\hline \multicolumn{2}{|l|}{$\begin{array}{l}\text { Como professor, devo propor situações-problema para o meu aluno e atividades que permitam ao aluno ir } \\
\text { resolvendo esse problema; dentro da sala, devo atuar como um mediador e um investigador no processo de } \\
\text { ensino-aprendizagem, o aluno tem um papel ativo na construção e reconstrução do seu conhecimento. }\end{array}$} \\
\hline \multicolumn{2}{|l|}{ Dimensão 5 - Como deve ser a minha forma de avaliar os meus alunos? } \\
\hline \multicolumn{2}{|l|}{$\begin{array}{l}\text { A minha avaliação deve cobrir o conteúdo trabalhado e com instrumentos individuais do tipo provas e listas de } \\
\text { exercícios preferencialmente, visando identificar o conhecimento adquirido pelo aluno durante o período. }\end{array}$} \\
\hline \multicolumn{2}{|l|}{$\begin{array}{l}\text { A minha avaliação deve cobrir o conteúdo trabalhado, os instrumentos não precisam ser especificadamente } \\
\text { individualizados, mas precisam me dar dados confiáveis para medir a aprendizagem e analisar o processo de } \\
\text { ensino-aprendizagem. }\end{array}$} \\
\hline $\begin{array}{l}\text { A minha avaliação deve privilegiar a mudança atitudinal do meu aluno, as habilidades e competências } \\
\text { construídas no processo de ensino-aprendizagem, por isso, a minha observação é um fator importantíssimo. }\end{array}$ & \\
\hline
\end{tabular}

Artigo recebido em 28/08/12. Aceito em 08/02/13. 